\title{
Endoloop ligation ("loop-and-let-go") of a large ileal lipoma by balloon-assisted enteroscopy
}

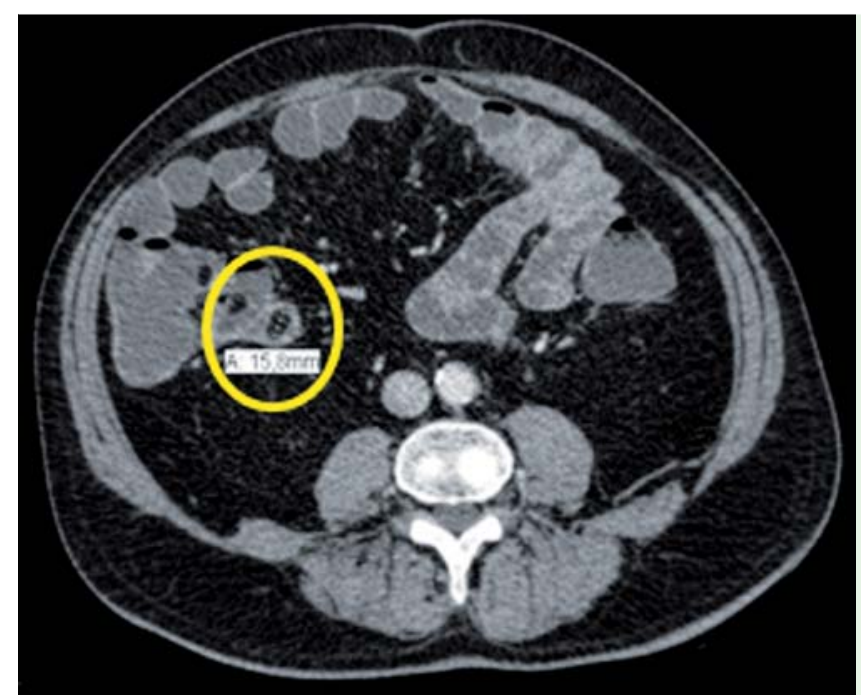

Fig. 1 Computed tomography (CT) enterogram showing a pedunculated, subepithelial mass (circled) in the distal ileum.

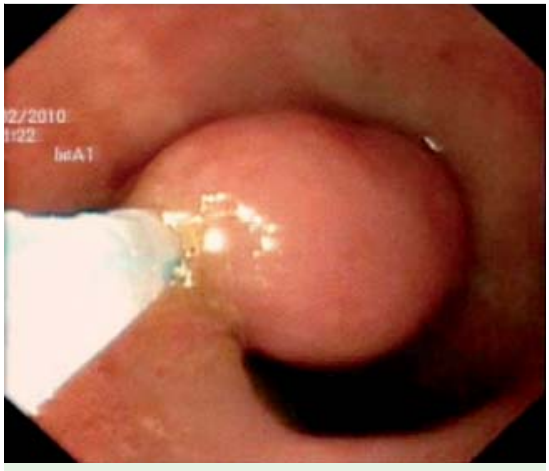

Fig. 2 Endoscopic appearance of the lipoma following Endoloop ligation showing mucosal congestion.

A 72-year-old man presented to our gastroenterology outpatient clinic with chronic abdominal pain, bloating, and past episodes of transient small-bowel obstruction. A computed tomography (CT) enterogram revealed a large, pedunculated subepithelial polyp in the distal ileum ( Fig. 1).

A decision was made to proceed to endoscopic treatment of the polyp because of its dimensions and the obstructive symptoms it was causing. Ileal intubation was achieved using a SIF-Q180 enteroscope (Olympus Medical Systems, Tokyo, Japan) and a subepithelial, pedunculated, yellow tumor with an endoscopic appearance compatible with a lipoma was identified in the distal ileum. A 30-mm Endoloop (MAJ-254; Olympus) was tightened around the tumor base until there was

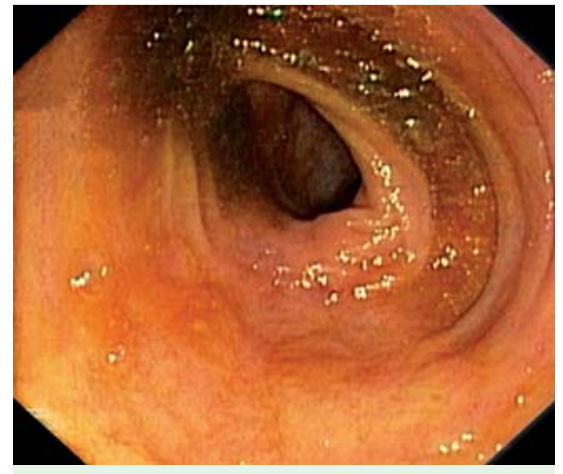

Fig.3 View of the distal ileum during enteroscopy 1 month after the initial procedure showing complete obliteration of the lipoma.

evidence of mucosal congestion ( $\bullet$ Fig. 2; - Video 1). A second enteroscopy was performed 4 weeks later, which confirmed that the polyp had been completely resected ( Fig. 3). Both the procedures were completed without any immediate complications. The patient remains asymptomatic over 12 months later.

Endoscopic snare cautery of large subepithelial tumors is discouraged because of the high risk of bowel perforation [1]. In 2006, Raju and Gomez described a technique using Endoloop ligation for a large

\section{Video 1}

Balloon-assisted enteroscopy showing a large, pedunculated lipoma being treated by the "loop-and-let-go" technique. pedunculated colonic lipoma [2], which demonstrated the feasibility of slowly and mechanically transecting a large subepithelial tumor. In a case series by Lee et al. that aimed to demonstrate the safety and feasibility of this technique in various subepithelial tumors, one ileal lipoma was removed, but a detailed description of the case was not given and only conventional endoscopes were used [3]. To our knowledge, we present the first description of this technique performed by balloon-assisted enteroscopy to remove a large ileal lipoma.

Endoloop ligation of subepithelial lesions presents an attractive technique because of the slow transection of the stalk of the polyp, which averts the risk of bowel perforation. The main caveat is that in most cases specimen retrieval is not possible.

Endoscopy_UCTN_Code_TTT_1AP_2AD

Competing interests: None

\section{R. Veloso, R. Pinho, A. Rodrigues, T. Pais, C. Fernandes, J. Carvalho, J. Fraga}

Department of Gastroenterology and Hepatology, Centro Hospitalar Vila Nova Gaia, Vila Nova de Gaia, Portugal

\section{References}

1 Pfeil SA, Weaver MG, Abdul-Karim FW et al. Colonic lipomas: outcome of endoscopic removal. Gastrointest Endosc 1990; 36: 435 438

2 Raju GS, Gomez G. Endoloop ligation of a large colonic lipoma: a novel technique. Gastrointest Endosc 2005; 62: 988 - 990

3 Lee SH, Park JH, Park D et al. Endoloop ligation of large pedunculated submucosal tumors. Gastrointest Endosc 2008; 67: $556-$ 560

\section{Bibliography}

Dol http://dx.doi.org/

10.1055/s-0031-1291752

Endoscopy 2012; 44: E176

(c) Georg Thieme Verlag KG

Stuttgart · New York

ISSN 0013-726X

\section{Corresponding author}

\section{R. Veloso, MD}

Centro Hospitalar Vila Nova Gaia -

Gastroenterology

Rua Conceicao Fernandes

Vila Nova de Gaia 4434-502

Portugal

Fax: +351-22-7865100

ricveloso@gmail.com 